diets are under investigation; $(b)$ that in families composed of persons of different sexes and ages the individual distribution of food among the members of the families can be expressed by the age and sex coefficients proposed by Atwater; (c) that published coefficients of wastage and proportional absorption are trustworthy. In addition to these special difficulties there are, of course, the usual pitfalls of statistics (errors of sampling, randomness or otherwise of sampiing, etc.).

From the evidence furnished by a short series of control experiments carried out by the Belgian inquirers, Slosse and Waxweiler, it seems likely that the American coefficient of reduction for sex, i.e. putting the consumption of an adult woman as 80 per cent. of that of an adult man, is not far from the truth; but, on the other hand, the American coefficients of consumption by children may be appreciably too small. The result is that, so far as reduction to "man values" is concerned, the English munition workers' mean is accurate, while the means of the other collections of data (which are reduced from family budgets comprising the nourishment of children as well as that of adults) may over-estimate the per caput "man" consumption, perhaps even as much as 20 per cent. Regarding the discount to be allowed for waste in preparation and non-assimilation, much depends upon the constituents of the diet, and the figure of 12 per cent. cannot be regarded as more than a very rough approximation.

Notwithstanding these limitations, the value of the data is considerable, and a study of them might induce some popular journalists and amateur food economists to moderate their strictures upon the extravagance of the English working classes which is alleged to have been fostered by the wartime rise in wages. The data do not suggest that the energy value of the diet consumed by so important a group of operatives as the munition workers is substantially greater than that received by persons of the same social and industrial class before the outbreak of hostilities. The distribution of energy between the three classes of foodstuffs has been different, an inevitable result of the potato famine and the appeals to eat less bread which characterised the period (spring and summer of 1917) during which the data were collected.

The general conclusion to be drawn from the statistics and the relatively few experiments available is that $3500-3800$ Calories in food as purchased are by no means an over-estimate of the nutritive requirements of an adult man engaged in moderately strenuous work. Recent work, indeed, confirms the vicw that Atwater's standard, so far as energy value is involved ( 3500 Calories), is not an extravagant one.

The British Medical Journal in its issue of December I directed attention to the fact that the Food Controller's voluntary ration for men on medium work provided about 2 Ioo Calories, leaving a deficit of I 400 Calories from the total of 3500 , which the evidence just set out shows to be a minimum requirement of workers in this class. Our contemporary concluded that a weekly conNo. $25 \pm 6$, VOL. IOO] sumption of $9 \frac{1}{2} \mathrm{oz}$. of fish and a daily consumption of one pint of milk were as much as could be hoped for from these so far unrationed articles, which leaves (cheese being notoriously scarce) a balance of nearly $95^{\circ}$ Calories to be obtained from potatoes, involving a daily consumption of more than two pounds. These facts show the urgent necessity of carefully organising the distribution of potatoes within the country and the obligation imposed upon persons living near the centres of supply (for instance, in suburbs with available allotments) to make free use of potatoes, thus helping to increase the quantities of cereals available in the industrial districts to which bulky vegetables are not easily transported. The gravity of the situation imposes a further duty upon the readers of a scientific journal, who must inculcate upon their friends the elementary principles of bioenergetics. That the relation between muscular work and food is as close as that between the mileage of an automobile and its consumption of petrol is a truth still hidden from nine out of ten educated persons; ignorance of the facts has been the parent of many untrue charges.

M. G.

\section{SCIENTIFIC WORK OF THE MEDICAL RESEARCH COMMITTEE.}

THE third annual report of the Medical Research Committee, which has recently been published (Cd. 8825: H.M. Stationery Office, price $6 d$. net.), testifies to a very large amount of work of a varied nature. A notable proportion of this has necessarily been devoted to problems atising, directly or indirectly, from the war. But the introductory remarks rightly point out that it is meaningless to try to separate the practical from the scientific aspects of any set of investigations. There are many problems, moreover, which the state of war brings into urgency for solution and, at the same time, offers unique opportunities for inquiry.

Limits of space forbid the reference in detail to all the questions dealt with in this very interesting and important report, and a mere list would be of little value or interest in itself. The report should be read carefully by all who have at heart the health and efficiency, not only of our sailors and soldiers, but also of the nation as a whole. It is proposed here rather to direct attention to a few results of general scientific importance.

It cannot escape notice how prominent have become the methods and results of the physiological laboratory. Two cases may be mentioned in illustration: the regulation of industrial work in relation to fatigue, and the supply of oxygen to men flying at high altitudes. In other instances our ignorance of fundamental physiological processes has been vividly brought home to us. One of these may be referred to in the next place.

Many diseases are caused, as is well known, by the invasion and presence in the blood of minute organisms of animal or plant nature, protozoa or bacteria. This is now, indeed, a matter of common knowledge. For a long time efforts have been 
made to discover some chemical agent which shall be able to kill these organisms, without injury to the tissues in which they flourish; but with little success. It is somewhat remarkable that most success has been obtained, not, as might have been expected, with the destruction of plant organisms, but with certain protozoa which have shown themselves to be readily susceptible to the toxic action of metals in organic combination. The present report gives an account of some steps towards the solution of the general problem. The hypochlorites introduced by Dakin have been found, in the hands of Lorrain Smith and Ritchie, to be comparatively non-toxic when injected into the veins in the form of "Eusol," while having an unmistakably beneficial effect in certain infections. But, as Dakin has shown, hypochlorites erter at once into combination with the proteins of the blood and cannot be supposed to exert a direct bactericidal action therein. The effect is apparently produced by some change in the blood itself, and it is interesting to note that Dale and Dobell have been led to the conclusion that the action of alkaloids on the amoeba of dysentery outside the body is not an index to their therapeutic efficiency, and that their influence on the tissues of the patient is of equal importance. On the other hand, the work of Dr. Carl Browning and his colleagues has brought forward a compound, related to the acidine series of dyes, which is apparently much more toxic to bacteria than it is to animal cells. On account of its colour, this antiseptic was originally called "flavine." It kills bacteria in concentrations in which it has but little effect on the activity of leucocytes, and is non-toxic in intravenous injection. Since the report was issued Dr. Browning has described experiments in which rabbits received intravenous injections of flavine without harm, but the serum of which was found in vitro to destroy bacteria. Opinions are, as yet, divided as to the value of flavine as a treatment for wounds. Some surgeons find that it prevents the normal growth of new tissue; but it is possible that the correct conditions have not yet been discorered.

In connection with the practical use of these various antiseptics, the law of distribution between phases, according to solubility, receives applica. tion in the value of the solutions of dichloroamine, acriflavine, and iodoform in fatty solvents, such as eucalyptol, paraffin, and soap.

The physiological importance of the presence in the organism ${ }_{1}$ of minute quantities of certain chomical substances, the constitution of which is, for the most part, unknown, becomes every day more evident. In two respects the report adds further valuable information. The "accessory factors " in food, without which growth is impossible and various diseases develop, appear to be of some variety and number. The growth factor in milk is shown by Winfield, in the laboratory of Hopkins, to be preserved in the drying process, a fact of practical bearing at the present time. The necessity of such factors for the growth of unicellular organisms themselves has been known for some time, but Miss Jordan Lloyd adds an impor- tant further contribution in her investigation of culture media for bacteria. She is of opinion that these growth factors act as catalysts. The chemical reactions, or some of them, necessary for growth proceed naturally at too slow a rate to be effective; but they can be accelerated by the presence of the factors in question. This hypothesis is in agreement with the fact that, although the substances are present in very small amount, they do not disappear from the organism for some days after the food has been deprived of them. They appear to exercise their function without themselves suffering chemical change. The second impcrtant addition to our knowledge concerns the internal secretion of the parathyroid glands. Noel Paton and his coadjutors show that the muscular tremors, which make their appearance when these glands are removed, are due to a disturbance of the metabolism of guanidine, which becomes present in excess under these conditions.

A brief reference should be made to the results of the laborious statistical work undertaken by the Committee, especially to that which shows the occurrence of two distinct types of micro-organisms producing phthisis. The comparative incidence of kidney disease in the ordinary population and in the men in the trenches also deserves mention. The value of the statistical method, under appropriate control, is well demonstrated.

A final reference may be made to the latest development of the Committee's work (see p. 78 of the report). The present writer, when visiting scme casualty clearing stations in France and Flanders in August last, found so great a divergence of views as to the cause and treatment of the "shock" following injury that, on his return, a special investigation committee was formed, consisting of surgeons at the front and laboratory workers in England. Results of much physiological importance may be expected, especially as to the cause of the low blood-pressure and its indirect effects. Several memoranda are already in course of publication.

W. M. Bayliss.

SCIENCE AND INDUSTRY IN AUSTRALIA.

THE Executive Committee of the Advisory Council of Science and Industry for the Commonwealth of Australia has recently published a report covering the period from its appointment to June 30 , 1917. ${ }^{1}$ The Advisory Council was originally appointed on March 16, I9 6 , and was intended to be a temporary body designed to prepare the way for a permanent Institute of Science and Industry, and to exercise in a preliminary way the functions that will in future belong to the institute.

The council as a whole has met only twice, but a vast amount of work has been done through committees. The Executive Committee has previously made two reports, but the document recently issued is a survey of the work done, and represents to a large extent the completion of the task of the temporary organisation in preparing the way for the permanent institute.

\footnotetext{
1 C. 7963. (Melbourne: Government Printer.)
}

NO. 25 I6, VOL. IOO] 